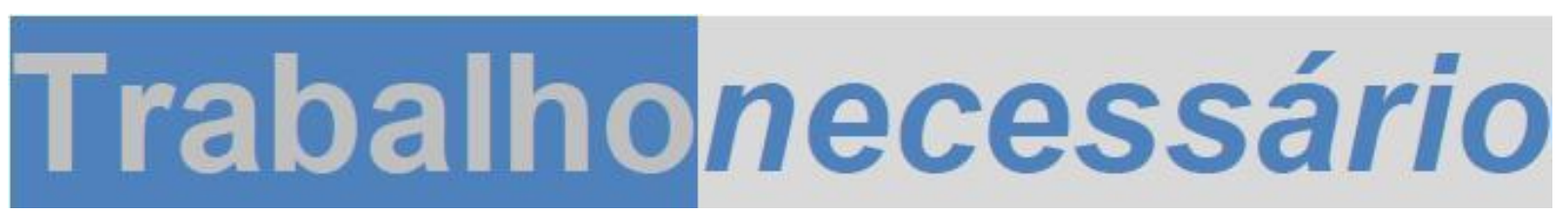

Issn: 1808 - 799X

ano 12 , no $18-2014$

\title{
MOVIMENTOS DE MORADORES E EDUCAÇÃO POPULAR NA REVOLUÇÃO PORTUGUESA DE 1974
}

\author{
Rui Canário ${ }^{1}$
}

\section{RESUMO}

O objetivo deste artigo é analisar uma das vertentes do movimento popular, representado pelos movimentos de moradores na Revolução Portuguesa de 1974/75, em luta por condições dignas de habitação. É minha intenção tornar mais visíveis os laços que unem esse movimento social a um processo de educação popular, processo esse que constitui um paradigma do modo como os trabalhadores podem de forma autónoma, e através da suas experiências de luta, realizar aprendizagens que modificam a sua visão do mundo e thes permite instituir novas formas de vida social.

PALAVRAS-CHAVE: movimentos sociais; educação popular; pobreza urbana

\section{ABSTRACT}

The purpose of this article is to analyse the struggle of the residents during the Portuguese Revolution of 1974-1975 for decent conditions of habitation, that is to say, a sort of popular movement. My intention is to stress the links that join this social movement to a process of popular education which constitutes a paradigm of the way the workers can, autonomously and through their struggle experiences, learn in a way that changes their vision of the world and allow them to create new forms of social life.

KEY WORDS: social movements; popular education; urban poverty.

\footnotetext{
${ }^{1}$ Professor Catedrático da Universidade de Lisboa. Instituto de Educação da Universidade de Lisboa
}

TrabalhoNecessário - www.uff.br/trabalhonecessario; Ano 12, № 18/2014. 


\section{Trabalhonecessário}

Issn: 1808 - 799X

ano 12, no $18-2014$

"O futuro está cheio de gritos. O futuro está cheio de revoltas. Como represar este rio transbordante

Que vai submergir as cidades?" Albert Cossery

\section{Introdução}

Na sequência do golpe de estado militar que se verificou em Portugal, em 25 de Abril de 1974, explodiu um movimento social popular que, segundo um prestigiado sociólogo, foi "sem dúvida o movimento social mais amplo e profundo da história europeia do pós-guerra" (Sousa Santos, 1992, p.27). Para um observador estrangeiro, Phil Mailer, viveram-se os "dois anos mais livres da história portuguesa" em que os trabalhadores "sonharam impossíveis" e tentaram criar uma sociedade mais justa: "É esta capacidade que faz dos seres humanos os sujeitos potenciais da história, em vez de seus perpétuos objetos" (Mailer,1978, p. 26).

$\mathrm{Na}$ continuidade de trabalhos anteriores (Canário, 2013) procuro neste texto fazer incidir a minha análise numa das vertentes do movimento popular que foi a luta dos moradores por condições dignas de habitação. É minha intenção tornar mais visíveis os laços que unem esse movimento social a um processo de educação popular, entendida como o reforço da autonomia das classes trabalhadoras na construção de outras formas de viver que materializam um processo de cariz emancipatório.

\section{As revoluções do futuro serão urbanas}

O modelo da revolução chinesa de proceder, como estratégia, ao cerco das cidades a partir dos campos foi dominante na segunda metade do século XX. Foi a partir de lutas de guerrilha com o apoio de camponeses que triunfou a revolução cubana e a reunificação e independência do Vietname. Foi esse mesmo modelo 


\section{Trabalhonecessário}

Issn: 1808 - 799X

ano 12, no $18-2014$

que, na sequência de lutas de libertação anticoloniais, permitiu a emergência de dezenas de novos países que deram outra configuração política à Organização das Nações Unidas (ONU). O 25 de Abril resulta de forma decisiva da luta anticolonial e representou o fim do império português.

No século XX a evolução demográfica e a crescente urbanização criam, na viragem do milénio, novas condições que fazem do espaço urbano o terreno de eleição para as lutas sociais emancipatórias, no século XXI. Passa a ser pelo menos admissível a hipótese de a cidade poder vir a substituir a empresa na centralidade dos conflitos sociais (Ascher, 1998).

O exemplo recente das lutas urbanas desenvolvidas no Brasil (Biar,2013), em vésperas do Campeonato do Mundo de Futebol de 2014, decorre de uma clara deterioração dos espaços de convivência e de socialização de uma vida urbana dominada pela lógica do mercado capitalista:

\footnotetext{
"As ruas foram alargadas, asfaltadas, surgiram viadutos, cavaram-se túneis, produzindo um ambiente cada vez mais hostil e tecnificado. Associados a estas transformações, o aumento das distâncias entre casa e trabalho, a periferização das grandes cidades e os processos de verticalização e segregação socio espacial impostos pela especulação imobiliária deterioraram ainda mais as condições de vida nos centros urbanos" (Duarte, 2013, p. 28).
}

É compreensível neste contexto que, tendo como ponto de partida reivindicações sobre os preços dos transportes públicos, se tenham mobilizado milhões de pessoas que ocuparam e se apropriaram do espaço público urbano. É neste sentido que a ocupação dos espaços públicos urbanos pelas classes trabalhadoras pode ser celebrada como uma conquista.

Segundo Ascher (1998) as grandes metrópoles urbanas mundiais deram lugar a novas configurações urbanas, denominadas de "metápoles", das quais resultam problemas de natureza social que convidam a uma mudança progressiva do modo de pensar e gerir a vida urbana, bem como do modo como as classes trabalhadoras se definem em relação a esse território alargado que engloba a 


\section{Trabalhonecessário}

Issn: 1808 - 799X

ano 12, no $18-2014$

produção, o consumo e o lazer. Desta forma, as cidades colocam-se "no centro das interrogações sobre o futuro das sociedades industrializadas e urbanizadas" (Ascher,1998, p.2). Este fenómeno ultrapassa o mero crescimento urbano que nos séculos XIX e XX esteve associado à industrialização dos países chamados "desenvolvidos". A urbanização estendeu-se ao designado Terceiro Mundo, abrangendo a maioria dos países e populações pobres onde, em vez de uma extensão ordenada, representa "uma rutura da tradicional sociedade de aldeia" (Mela, 1999, p.47).

O crescimento exponencial dos espaços e das populações urbanas, que ultrapassou largamente as previsões feitas pelo Clube de Roma nos finais dos anos 60, redundou numa explosão do número de bairros e casas com excesso de população sem condições mínimas de equipamentos de infraestrutura, nomeadamente água potável e outras condições sanitárias. É neste sentido que se pode falar de uma generalização das favelas, como faz Mike Davis (2006, p.28):

“(...) as cidades do futuro, em vez de feitas de vidro e aço, como fora previsto por gerações anteriores de urbanistas, serão construídas em grande parte de tijolo aparente, plástico reciclado, blocos de cimento e restos de madeira. Em vez das cidades de luz arrojando-se aos céus, boa parte do mundo urbano do século XXI instala-se na miséria, cercada de poluição, excrementos e deterioração".

A pobreza urbana, acompanhada de agravamento global das desigualdades e dos fenómenos de segregação espacial, torna-se o principal problema civilizacional à escala planetária. Num mundo urbanizado e proletarizado, sem camponeses e com défice de emprego, em vez de fatores de crescimento e prosperidade as cidades tornam-se "o depósito de lixo de uma população excedente que trabalha nos setores informais de comércio e serviços, sem especialização e desprotegida" (Davis, 2006, p.175).

Esta urbanização com a produção de uma humanidade "excedentária" configura-se como mais uma variante da "questão social" que desde o início da

TrabalhoNecessário - www.uff.br/trabalhonecessario; Ano 12, № 18/2014. 


\section{Trabalhonecessário}

Issn: 1808 - 799X

ano 12, no $18-2014$

modernidade se afirmou como o antagonismo entre o capital e o trabalho. Esta mais recente metamorfose é indissociável do chamado "capitalismo de desastre" (Klein, 2009), ou seja, do triunfo à escala global de uma orientação económica e financeira decorrente do chamado "Consenso de Washington", que consagrou a nível global o domínio do capital financeiro e dos grandes grupos multinacionais.

No atual quadro civilizacional serão cada vez mais importantes os estudos que permitam dar visibilidade e compreender o sentido dos movimentos sociais urbanos e da sua pertinência para superar a lógica do capitalismo e contribuir para a invenção de novas formas de vida urbana que articulem de modo virtuoso o trabalhar, o viver e o aprender. É nesta perspetiva que deve ser entendido o nosso propósito de analisar os movimentos de moradores na revolução portuguesa de 1974. Eles são de algum modo percursores das lutas urbanas que já existem e se anunciam neste século.

\section{A habitação e a "questão social" no Portugal do século XX}

Em novembro de 1967, a área metropolitana de Lisboa foi atingida por chuvas diluvianas que tiveram efeitos catastróficos em algumas zonas de habitação da periferia urbana. O governo procurou, através da censura, ocultar a dimensão do desastre, que provocou uma onda de solidariedade dos estudantes universitários de Lisboa. As mortes foram numerosas, cerca de cinco centenas segundo a avaliação de um jornal independente do governo (Diário de Lisboa), mas seletivas do ponto de vista social, colocando a nu o problema social da habitação. Segundo Pimentel (2013, p.473): "Mais de mil pessoas ficaram desalojadas, na sua maioria moradores de bairros de lata ou de habitações precárias das regiões mais afetadas, onde as águas chegaram a atingir até três metros de altura".

$\mathrm{Na}$ sequência de uma elevada taxa de crescimento económico nos anos 60 , acompanhada de um crescimento dos principais centros onde se concentrava

TrabalhoNecessário - www.uff.br/trabalhonecessario; Ano 12, № 18/2014. 


\section{Trabalhonecessário}

Issn: 1808 - 799X

ano 12, no $18-2014$

o proletariado industrial (Lisboa, Porto e Setúbal), a situação da habitação popular em meio urbano era um problema explosivo nas vésperas do 25 de Abril de 1974. Já no século XIX a questão da habitação aparecia intimamente associada à "questão social". Ela era paralela à emergência de um proletariado industrial urbano que ensaiou os primeiros passos na via do associativismo de classe (Canário, 2009).

Ao longo do século XX o problema agravou-se. Desde o início do século as classes trabalhadoras estavam condenadas a "habitar os chamados bairros de lata, constituídos por barracas improvisadas". A partir dos anos cinquenta "começaram a construir-se, não já na cidade de Lisboa mas na sua periferia os chamados 'bairros clandestinos', à margem de qualquer licenciamento camarário" (Pereira, 1994).

Na década de 60, ao mesmo tempo que se constituía a zona metropolitana de Lisboa, a cidade suburbanizava-se e emergia como uma "cidade metrópole dualista (Nunes, 2013, p.96). No início dos anos 90, ainda os bairros de barracas eram encarados pelo poder público como "chagas sociais", mas em Portugal, através dos Programas de Realojamento (deslocalização da população e alojamento em altura), reproduziu-se a "habitação social europeia do pós-guerra, produzindo pequenos guetos nos subúrbios das áreas metropolitanas" (Cachado, 2013, p.148).

No período inicial da adesão à União Europeia, a "prosperidade" e a "modernização" testemunharam, nos anos 80 e 90, níveis crescentes de pobreza urbana e de polarização social. A estigmatização dos bairros populares e a emergência de sentimentos de insegurança alimentaram a segregação social no espaço urbano, polarizada entre os "bairros acossados" e a crescente importância dos condomínios fechados (Raposo, 2008).

Evoluções de sentido idêntico se verificaram no Porto e em Setúbal: o crescimento urbano acompanha a industrialização e a marca das habitações 


\section{Trabalhonecessário}

Issn: 1808 - 799X

ano 12, no $18-2014$

populares é, no início dos anos 70, a de "precariedade habitacional" (Queirós, 2013).

Em Setúbal, segundo Guimarães (1994, p.529), o crescimento industrial no século XX "acompanhou um sentimento de perda de qualidade do espaço vivido", particularmente no que concerne "às condições de alojamento dos pobres". Em meados do século $X X$ a qualidade das habitações populares poderia ser apresentada como: "Espaços exíguos e sobrelotados, húmidos e mal cheirosos, insalubridade, má qualidade de construção, preços elevados, são estes os qualificativos mais frequentes utilizados na imprensa para descrever o alojamento dos trabalhadores". O problema do elevado preço dos arrendamentos explica a importância do que viria a ser, no período revolucionário, a luta por fixar um preço máximo de arrendamento por assoalhada (500 escudos, ou seja, em termos atuais, dois euros e meio).

\section{Abril: O povo apropriou-se das cidades}

Segundo um observador direto da época, em Lisboa, as pessoas convenceram-se de que podiam mudar a sua vida:

"A recordação que tenho desses tempos é de que as pessoas tinham qualquer coisa a dizer sobre o seu destino, intervir e modificar o futuro. las a um bairro de lata e havia pessoas organizadas, comissão de moradores, grupo de teatro, toda a gente estava empenhada em construir qualquer coisa, o seu próprio futuro" (Vários, 1994, p.21).

O mesmo observador dá-nos um testemunho direto de um processo de ocupação de casas nos dias imediatos ao golpe de estado, a ocupação do Bairro 2 de Maio:

"Foi uma grande manifestação de pessoal das barracas, que sobe a calçada da Ajuda em direção ao bairro da Fundação Salazar, onde havia uma série de prédios acabados e desocupados. Foi inesquecível ver a manifestação entrar no bairro e cinco minutos depois as janelas todas abertas, com toda a gente à janela a gritar: Já tenho uma casa! 


\title{
Trabalhonecessário
}

Issn: 1808 - 799X

ano $12, \mathrm{n}=18-2014$

Já tenho uma casa! Era uma coisa indescritível, o poder daquele pessoal a entrar por ali dentro, a ocupar, e depois a felicidade que sentiram, ao apropriarem-se de uma casa" (Vários, 1994, p.21-22).

Após a ocupação das casas, e depois de rebatizado o bairro (social), os moradores passaram a organizar-se, como explicitaram em comunicado próprio:

\begin{abstract}
"Nós ocupámos as casas. Agora temos que organizar a sua ocupação e ver o que há a fazer. São os mais necessitados que precisam de maior ajuda. Devemos ajudar-nos uns aos outros e trabalhar para a unidade. Organizaremos uma lista dos que vão para as casas já acabadas e, uma vez aprovada por nós, tem que ser levada à prática, haja o que houver. O povo é que tem de fazer isto com as suas próprias mãos" (Vários, 1994, p.23).
\end{abstract}

Por outro lado, noutras zonas dos subúrbios de Lisboa, como é o caso de

Chelas, "começou a catadupa de ocupações", e "estabeleceu-se uma grande fraternidade" como sublinha um outro participante direto das ocupações no Bairro social de Chelas - Cabo Ruivo:

\begin{abstract}
"Havia Comissões de Moradores e Comissões de Prédio. Tudo estava estruturado. Havia reuniões de prédio, de rua, de bairro, conforme o assunto. Lembro-me de reuniões nas escadas do prédio onde toda a gente participava e dava opiniões: os chamados chefes de família, mulheres de filhos ao colo a dar de mamar, velhotes, putos como eu. As fronteiras das idades estavam esbatidas. Depois de discutido no prédio, o assunto ia para a Comissão de Moradores" (Vários, 1994, p.106 - 107).
\end{abstract}

Na cidade do Porto, entre Abril e Junho de 1974, irrompeu o movimento dos moradores pobres, que tinha antecedentes em lutas anteriores ao 25 de Abril nos bairros camarários, que viria a abarcar todo o período revolucionário, embora com vagas marcadas por diferentes tipos de reivindicações. Segundo Maria Rodrigues (1999, p.72-73) o movimento começou, de forma marcadamente espontânea, com a exigência de resposta às deficientes condições de habitação ("sim às ocupações", "casas sim, barracas não").

Após o 28 de Setembro de 1974 (em que foi derrotada a ala militar, de direita, spinolista) o movimento de moradores "avolumou-se e fortaleceu-se". Aumentou o número de Comissões de Moradores e surgiram "as primeiras

TrabalhoNecessário - www.uff.br/trabalhonecessario; Ano 12, № 18/2014. 


\section{Trabalhonecessário}

Issn: 1808 - 799X

ano 12 , no $18-2014$

estruturas de coordenação das comissões e associações de moradores". O teor das palavras de ordem acompanha as novas "nuances": "População organizada, habitação conquistada".

Em 1975, acompanhando a radicalização do conflito social e político, radicalizaram-se também as palavras de ordem ("Casas para todos, contra o capitalismo") exprimindo a vontade de ir mais fundo na subversão da ordem social capitalista: "o movimento de moradores questionava as formas de propriedade e de apropriação do solo e condenava o papel da renda fundiária no processo de acumulação capitalista".

Segundo Maria Rodrigues (1999, p.76), a partir de Abril de 1975 constituiuse o Conselho Revolucionário de Moradores do Porto (formado por dois representantes de cada associação ou comissão de moradores), que funcionou "como um verdadeiro órgão de coordenação do movimento popular urbano do Porto", cuja representatividade viria a ser consagrada com a participação popular na gestão municipal por integração de delegados no Conselho Municipal.

Em artigo recente, João Queirós (2013, p.121) sintetiza de forma muito clara a presteza e grau de estruturação demonstrados pelos moradores pobres do Porto, no aproveitamento da "janela de oportunidade aberta pelo golpe militar de 25 de Abril de 1974". O movimento de ocupações percorre toda a cidade, sucedendo-se a criação de novas Comissões de Moradores, que eram responsáveis:

“(...) por inúmeras ações, antes e depois da institucionalização e arranque das operações de renovação urbana, desde a realização de levantamentos sociográficos da população local à gestão dos processos de realojamento, passando por ações de protesto e pressão pública".

Na cidade de Setúbal, o 25 de Abril de 1974 e os seus desenvolvimentos políticos foram vividos na alegria e euforia registados nos principais centros urbanos. Durante o período revolucionário, segundo o testemunho de um 


\title{
Trabalhonecessário
}

Issn: 1808 - 799X

ano $12, \mathrm{n}$ - $18-2014$

trabalhador regressado da Guiné, onde combatia no exército colonial, "Setúbal fervilhava":

\begin{abstract}
"Quando cheguei a Setúbal, foi um choque ver as pessoas completamente diferentes, nas ruas a reivindicar e a trabalhar em conjunto nas Comissões de Trabalhadores e de Moradores. Setúbal fervilhava e, passado o choque da surpresa, integrei-me e comecei a viver aqui a revolução. Não parei mais, quer como trabalhador quer como ativista sindical pois estava consciente daquilo que defendia. Apesar da revolução se ter desencaminhado, continuei a defender esses princípios e a ser ativo, pois acho que todos devemos exercer o nosso direito de cidadania" (Brinca e Baía, v. II, p.173).
\end{abstract}

Neste ambiente inicia-se em Setúbal o movimento de ocupação de casas e de recusa das rendas especulativas. Os moradores partiram à conquista da cidade: "Num movimento espontâneo, são ocupadas nos primeiros 10 dias de 1500 a 2000 casas de habitação social" (DOWS e outros, 1978, p.46).

Um interveniente direto relata o modo como se processou a dinâmica do movimento no Bairro da Fundação Salazar, em 8 de Maio de 1974 (Brinca e Baía, 2002, vol. I, p.29):

"Estava com três pessoas, uma das quais moradora na Fundação Salazar, junto à entrada do bairro. Como o nome já não dizia nada a ninguém resolvemos mudá-lo para uma data que nos dizia muito. Destruímos a placa com o nome do bairro e batizámo-lo de Bairro 25 de Abril. (...) Pouco tempo depois, era ver dezenas de famílias de trouxa às costas para ocuparem as casas da Fundação Salazar. Tudo isto foi muito rápido, as coisas aconteciam umas em cima das outras, mas do que me lembro melhor é dos miúdos. Das expressões de felicidade de dezenas de crianças que nunca tiveram nada e que agora iam ter uma casa com janelas, vidros, casa de banho e tudo..."

Um outro morador relembra o processo de formação de uma Comissão de Moradores, em 22 de Julho de 1974:

\begin{abstract}
"Estava com um grupo de vizinhos e amigos do Bairro de Azeda de Baixo, onde moro há mais de 30 anos, nesse dia decidimos formar a Comissão de Moradores, uma das primeiras do concelho de Setúbal. Esta decisão surgiu depois de vários encontros e discussões sobre os problemas do bairro que, para serem resolvidos tinham de contar com um grupo organizado de representantes dos moradores. Assim, nesse dia formámos a Comissão com cinco ou seis moradores e o resto do pessoal foi aparecendo à medida que íamos passando a palavra. " (Brinca e Baía, 2002, vol. I, p.69).
\end{abstract}




\section{Trabalhonecessário}

Issn: 1808 - 799X

ano 12, no $18-2014$

A luta desenvolvida pelos moradores do Bairro de Castelo Velho, em que a mobilização da população acontece no início de Maio de 1974, ilustra de forma exemplar a dinâmica do movimento urbano em Setúbal. Essa dinâmica é retratada numa obra com o sugestivo título de "Fartas de viver na lama" (Pinho, Gonçalves e Taurino, 2002). Formada a Associação de Moradores, "a sede de liberdade e participação gera uma adesão praticamente total do bairro. Surgem ciclos de cinema, inicia-se mesmo um curso de alfabetização" (p. 87).

Em Julho de 1974, no decurso de uma festa no pavilhão do Clube Naval Setubalense, animada por conhecidos cantores de intervenção, a comissão representativa do bairro tomou a palavra para afirmar: “(...) Nós, moradores do Castelo Velho (...) operários de fábricas, da construção, pescadores, (...) exigimos casas decentes (...) assim como para todos os outros que se encontram nas mesmas condições, em Setúbal ou qualquer parte do país." (p.

59).

\footnotetext{
"Depois de meses e meses de sacrifícios, finalmente os moradores do Castelo Velho puderam contemplar todo um trabalho de tenacidade e luta: as primeiras 30 casas foram entregues. (...) Pouco importou a chuva que copiosamente caía, que nos fazia afundar os pés na lama. Era a festa da malta do Castelo. Lá estavam todos, mulheres, homens e crianças. A beber do mesmo copo, a comer do mesmo prato. Era uma festa de amigos (...)" (p. 125).
}

\section{Lutas urbanas e processos de aprendizagem popular}

As lutas protagonizadas pelos moradores no pós-25 de Abril representaram, na sociedade portuguesa, a aprendizagem, por parte das classes trabalhadoras de formas alternativas de viver na cidade e de a transformar. Como afirma Rodrigues (1999), para lá dos objetivos mais imediatos de melhorar as condições de alojamento, a luta dos moradores tinha um horizonte muito mais largo que englobava a luta por instituir modos de vida solidários, bem como o acesso generalizado aos bens culturais. A autora dá a palavra aos moradores de 


\title{
Trabalhonecessário
}

Issn: 1808 - 799X

ano $12, \mathrm{n}$ - $18-2014$

Vitória (Porto) no sentido de melhor ser explicitado o alcance largo de um processo que abrange várias esferas da vida social:

\begin{abstract}
"Uma Comissão de Moradores deve sempre ser criada com a finalidade de ajudar a população a resolver os problemas com que se debate, devendo a sua atuação estenderse a todos os campos com especial atenção para as condições de habitação, higiene, saúde, cultura, desporto, problemas de infância, terceira idade e tudo o mais que se relacione com as condições de vida" (p. 105).
\end{abstract}

Sendo no espaço urbano que se organiza a reprodução social do trabalho, a sua estrutura projeta no espaço físico e social as relações da sua própria formação social (capitalista). É a própria natureza dessa formação social que é posta em causa e provisoriamente superada através das lutas dos moradores que assumem o direito à palavra e ensaiam modos de gestão urbana baseados no auto governo e na democracia direta. Como refere Dows e outros (1978) criam-se novas formas e modalidades de informação e de comunicação.

"O panfleto, o comunicado, o discurso de rua, o grupo que discute animadamente em pleno bairro e em todos os pontos de encontro que a cidade oferece, o meeting na praça ou na fábrica, o cartaz e o mural, as reportagens diretas ou os filmes sobre greves, ocupações, manifestações, etc... em que são os próprios participantes que comunicam os seus pontos de vista e explicam os seus problemas" (p. 13)

Ao mesmo tempo que se organizam por bairro (prédio, ou rua), os moradores aprendem a coordenar as suas ações com outras unidades congéneres. Num primeiro momento criam-se ligações horizontais com outras comissões de moradores que, no caso de Setúbal, viriam a dar origem a um órgão de coordenação ao nível da cidade, e à interligação das comissões de moradores com as comissões de trabalhadores, as comissões de soldados e a ligação direta da cidade ao campo através da compra direta a trabalhadores organizados em cooperativas agrícolas. Segundo Dows e outros (1978, p.58), as Comissões de Moradores, nomeadamente no caso de Setúbal, corresponderam à base organizativa de um movimento social que se "desenvolveu até ao ponto de constituir um verdadeiro duplo poder ao nível da cidade". 


\section{Trabalhonecessário}

Issn: 1808 - 799X

ano 12, no $18-2014$

A emergência deste fenómeno de duplo poder que, por definição, é a marca de uma situação revolucionária é referida por Raquel Varela (2014, p.253) que indica o final de 1974 e os primeiros meses de 1975 como o período temporal em que emergem os órgãos de coordenação dos movimentos de moradores: $A$ Comissão Central de Comissões de Moradores dos Bairros Camarários do Porto (criada a 13 de dezembro de 1974); a Intercomissões dos bairros pobres e de lata de Lisboa (criada em Janeiro de 1975); a Intercomissões dos bairros de Barracas em Setúbal (Fevereiro de 1975).

No caso do Bairro do Castelo Velho, em Setúbal, a interação entre os moradores e os técnicos (principalmente arquitetos) do SAAL (Serviço Ambulatório de Apoio Local), criado pelo governo para dar apoio aos moradores na melhoria das suas condições de habitação, permitiu realizar aprendizagens que tornaram possível que os próprios moradores fossem os administradores da urbanização, controlando diretamente dinheiros públicos de valor elevado.

Como referem Pinho, Gonçalves e Taurino (2002, p.95):

"[os moradores] Foram administradores. Tinham que administrar o trabalho que executavam, o trabalho dos pedreiros, dos eletricistas - tudo isso eram eles que tratavam. Faziam os pagamentos, aquisição de materiais. Gente analfabeta a administrar!"

É neste processo que apreendem competências e conceitos no campo da arquitetura, do urbanismo, do controlo orçamental. A participação nas reuniões do

Comité de Luta de Setúbal "foi um campo em que as comissões e as associações de moradores fizeram uma grande aprendizagem e deram um importante contributo" (p. 140).

\section{Educação popular e autonomia - Considerações finais}

Os movimentos de moradores na revolução portuguesa de 1974/75 constituem um paradigma do modo como os trabalhadores podem de forma

TrabalhoNecessário - www.uff.br/trabalhonecessario; Ano 12, № 18/2014. 


\section{Trabalhonecessário}

Issn: 1808 - 799X

ano 12, no $18-2014$

autónoma, e através da suas experiências de luta, realizar aprendizagens que modificam a sua visão do mundo e lhes permite instituir novas formas de vida social. É esta aprendizagem na ação, livre das tutelas do Estado, que está no cerne do que podemos designar por educação popular. Uma educação que é promovida e construída pelos novos órgãos sociais que resultam da ação transformadora dos movimentos sociais de cariz anticapitalista. Como sublinhou André Gorz (1997, p.114) a educação, em contraste com o condicionamento, a doutrinação e o treino visa no essencial "fazer nascer no indivíduo a capacidade de tomar conta de si próprio de modo autónomo" e esta capacidade não pode ser ensinada. Ela é aprendida na ação, de forma individual e coletiva.

É esta aprendizagem na ação que caracteriza os movimentos de moradores que temos vindo a referir. André Gorz atribui uma grande ênfase à importância das mudanças no campo do urbanismo que, segundo ele, são fundamentais na construção de formas sociais alternativas ao capitalismo. Uma nova vida urbana deverá ser concebida no sentido de "facilitar as auto atividades, as trocas, a criação e a cooperação". Mudando a cidade, muda-se "a maneira como as pessoa vivem as relações e a sua inerência ao mundo":

"A reconstituição de um mundo vivido e suscetível de ser vivido supõe cidades policêntricas, inteligíveis, em que cada bairro ou lugar de vizinhança oferece uma gama de lugares acessíveis a todos, a qualquer momento, para as auto atividades, para as auto produções, as auto aprendizagens, as trocas de serviços e de saberes" (Gorz, 1997, p.163).

Esta visão sobre a relação entre a mudança social, a mudança urbana e a aprendizagem é consonante com o modo como Gramsci (2004, p.50) nos convida a olhar o papel da educação. Numa perspetiva de construção da democracia evoluiremos para um progressivo apagamento da distinção entre governantes e governados. Neste sentido a educação deve tornar possível que cada cidadão se torne potencialmente num governante. A educação popular só é possível na luta desenvolvida pelos trabalhadores para a sua própria emancipação. É este o caso 


\section{Trabalhonecessário}

Issn: 1808 - 799X

ano 12, no $18-2014$

dos movimentos de moradores e das lutas urbanas que ocorreram em Portugal na fase revolucionária de 1974/75.

\section{Referências:}

ASCHER, François (1998). Metapolis. Acerca do futuro da cidade. Lisboa: Celta BIAR, Marcelo, Org. (2013). E o povo reinventou as ruas: olhares diversos sobre as manifestações de 2013. Rio de Janeiro: Editora multifoco.

BRINCA, Pedro e BAÍA, Etelvina (2002). Memórias da Revolução no Distrito de Setúbal, 25 anos depois. Setúbal: Setúbal em rede, 2 vols.

CACHADO, Rita (2013). O Programa Especial de Realojamento. Ambiente histórico, político e social. Análise Social, 206, 134-152.

CANÁRIO, Rui (2013). Educação popular e "questão social" na modernidade europeia. In: STRECK, Danilo e ESTEBAN, M. T. (Orgs). Educação popular. Lugar de construção coletiva. Editora Vozes: Petrópolis, 334-347.

CANÁRIO, Rui (2009). Associativismo e educação popular. In: Canário, Rui e Rummert, Sónia, Orgs. Mundos do trabalho e aprendizagem. Lisboa: Educa. DAVIS, Mike (2006). Planeta favela. S. Paulo: Boitempo Editorial.

DOWS, Chip e outros (1978). Os moradores partiram à conquista da cidade. Comissões de Moradores e Lutas Urbanas em Setúbal, 1974 - 1976. Lisboa: Armazém das Letras.

DUARTE, Cristóvão (2013). Uma cidade muda, não muda! In: Biar, Marcelo, org.

E o povo reinventou as ruas: olhares diversos sobre as manifestações de 2013. Rio de Janeiro: Editora multifoco.

GORZ, André (1997). Misères du présent. Richesses du possible. Paris : Galilée. KLEIN, Naomi (2009). A doutrina do choque. Capitalismo de desastre. Lisboa: Smart Book.

GRAMSCI, Antonio (2004). Cadernos do Cárcere. Volume 2. Rio de Janeiro: Civilização Brasileira. 


\section{Trabalhonecessário}

Issn: 1808 - 799X

ano 12, no $18-2014$

MAILER, Phil (1978). Portugal: a revolução impossível? Porto: Afrontamento.

MELA, Alfredo (1999). A sociologia das cidades. Lisboa: Estampa.

NUNES, João Pedro (2013). O programa Habitações de Renda Económica e a constituição da metrópole de Lisboa (1959 - 1969). Análise Social, 206, 82 - 100. PEREIRA, Nuno Teotónio (1994). Pátios e vilas de Lisboa, 1870 - 1930: a promoção privada do alojamento operário. Análise Social, 127, 509 - 524.

PIMENTEL, Irene (2013).História da oposição à ditadura. 1926-1974. Porto: Figueirinhas.

PINHO, Jaime, GONÇALVES, Fernanda e TAURINO, Leonor (2002). Fartas de viver na lama. 25 de Abril, o Castelo Velho e outros bairros SAAL do distrito de Setúbal. Lisboa: Edições Colibri.

QUEIRÓS, João (2013). Precariedade habitacional, vida quotidiana e relação com o Estado no centro histórico do Porto na transição da ditadura para a democracia. Análise Social, 206, 102-133.

RAPOSO, Rita (2008). Condomínios fechados em Lisboa: paradigmas e paisagens. Análise Social, 186, 109 - 131.

RODRIGUES, Maria (1999). Pelo direito à cidade. O Movimento de Moradores no Porto (1974/76). Porto: Campo das Letras.

SOUSA SANTOS, Boaventura (1992). O Estado e a Sociedade em Portugal (1974- 1988). Porto: Afrontamento.

VARELA, Raquel (2014). História do Povo na Revolução Portuguesa 1974/75. Lisboa: Bertrand.

VÁRIOS (1994). O futuro era agora. O movimento popular do 25 de Abril. Lisboa: Edições Dinossauro.

Recebido em junho de 2014 Aprovado em junho de 2014 